\title{
EFFECT OF CAD/CAM TECHNOLOGY SYSTEM AND TIMING OF DENTIN SEALING APPLICATION ON HYBRID CERAMIC ENDO-CROWNS MARGINAL FIT
}

\author{
Amany M. Korsel*
}

\begin{abstract}
Purpose: The purpose of this study was to determine the influence of CAD/CAM system type and immediate dentin sealing (IDS) on the marginal fit of hybrid ceramic endocrowns.

Material and Methods: Forty recently extracted lower molars were selected, and standardized prepared to receive endocrown restorations .All restorations were milled in hybrid ceramic (VITA ENAMIC® for CEREC $® /$ inLab®, VITA Zahnfabrik H. Rauter GmbH \& Co.KG., Germany). The teeth were assigned to 4 groups $(n=10)$ according to: (1) The type of CAD/CAM system: a) DOF system (DOF Inc., Seoul, South Korea) and b) CEREC inLab system (Sirona Dental Systems, Germany)], (2) The timing of dentin sealing. a) Immediate dentin sealing (IDS) and b) Delayed dentin sealing (DDS)].The vertical marginal gaps were then measured using measuring Stereomicroscope (Nikon Eclips E600, Tokyo, Japan). The obtained data were submitted to Kruskal-Wallistest $(\alpha=.05)$.
\end{abstract}

Results: All marginal gap values found in this study were below the clinically acceptable value of restorations which is $120 \mu \mathrm{m}$. A significant difference was found between group 1 (DOF, IDS), group 2 (DOF ,DDS) and between group3 (CEREC , DDS), group 4 (CEREC, IDS) also between group 2(DOF, DDS) and 4 (CEREC, IDS) .

Conclusion: This study concluded that there is a significant effect of the CAD \CAM system and the timing of dentin sealing application on the marginal fit of the Hyprid ceramic endocrown restorations, where CEREC in-lab system and the immediate dentin sealing decrease the marginal adaptation .

KEY WORDS: Endocrowns, CAD/CAM, marginal fit, immediate dentin sealing and hybrid ceramics.

* Ass. Prof in Fixed Prosthodontic Depart. Faculty of Dentistry. Tanta University 


\section{INTRODUCTION}

Restoration of endo-dontically treated teeth (ETT) still a widely controversial topic ${ }^{(1)}$. It is widely accepted nowadays that readymade or custom-made metallic posts or other types of post material do not reinforce the teeth but they even contribute to their weakness. ${ }^{(2)}$

The advancements of adhesive techniques, and the shift toward minimally invasive restorations has promoted the introduction of new treatment options as endocrown. ${ }^{(3)}$

Endocrown is a one-piece all-ceramic restoration overlay bonded on ETT, with an extension inside the pulp chamber. This conservative approach preserves tooth tissues and allows re-intervention in the case of endodontic retreatment. Also, the conservation of peripheral enamel facilitates bonding of the restorations to it, leading to better marginal stability ${ }^{4}$. When compared to post and core, endocrowns don't require many technical steps such as post space preparation and cementation, core build-up and crown lengthening which increase treatment time and costs. Several in vitro ${ }^{(3-5)}$ and in vivo studies have proven the suitability of this adhesive restoration above all for molars ${ }^{(6,7)}$.

A lot of materials can be used to fabricate an endocrown like feldspathic, glass-ceramic and the newest monolithic hybrid CAD/ CAM ceramic and composite blocks ${ }^{(8)}$.

CAD-CAM systems present an alternative to the traditional method of fabricating indirect restorations, reducing time and $\operatorname{cost}^{(9)}$ because these systems do not require a firing procedure ${ }^{(10)}$, as the hybrid ceramic block, Vita -Enamic. The material consists of two interpenetrating networks, a glassceramic network and a methacrylate polymer network, with a proportion of $84 \%$ and $16 \%$ respectively (by weight). It is indicated for single restoration like crowns, veneers, inlay and onlays, and combines the advantages of both ceramics and composites $^{(11)}$.
The marginal fit of CAD/CAM restorations is influenced by several factors such as margin configuration, cement space, type of cement used, cementation technique ${ }^{(12-15)}$, scanning software and milling system ${ }^{(16,17)}$.

Despite of the improvements of CAD $\backslash C A M$ systems, scanning and milling restorations for complex preparations are still challenging ${ }^{(18)}$ because milling machines may not be able to reproduce the contour of restoration in areas that are smaller than the diameter of the milling burs ${ }^{(19)}$. So the preparation design should take this into account ${ }^{(20)}$. Wide shoulders and sharp angles should be avoided to allow adequate access of milling burs ${ }^{(21-23)}$.

Marginal fit is the most important factor in the success of restorations ${ }^{(24) .}$ It includes both vertical and horizontal gaps $^{(25)}$. Horizontal discrepancies, such as crown overhangs can be adjusted to some degree intraorally ${ }^{(25)}$. Vertical marginal gaps may be sealed with luting cement but it will be rough, porous, and can dissolve. The larger the marginal discrepancy, the faster will be the rate of cement dissolution ${ }^{(26)}$.

The traditional technique used for producing indirect restorations consists of making an impression of the tooth immediately after preparation and luting a provisional restoration with provisional cement. Once the permanent restoration is ready, the provisional material is removed and an adhesive system is applied to the tooth, followed by a resin cement for the adhesive luting procedure ${ }^{(27)}$.

Researchers have pointed out that adhesive systems bond better to freshly cut dentin rather than to dentin contaminated with temporary cement materials. ${ }^{(28)}$ This contamination with the temporary restoration may lead to micro leakage ${ }^{(29)}$. The immediate dentin hybridization or immediate dentin sealing (IDS) technique was suggested to avoid this problem ${ }^{(30)}$. This IDS technique consists of the application of an adhesive system immediately after the tooth preparation and before the conventional 
impression. Higher bond strengths have been recorded when the IDS technique was immediately applied ${ }^{(31-36)}$.

When using CAD/CAM technologies the tooth can be prepared and the restoration finished and cemented in a single visit, excluding the need for temporization and dentin contamination, which may compromise effective bonding of the restoration $^{(37)}$. However, decalcified collagen may collapse during the permanent cementing procedure due to the pressure applied in the process, leading to a faulty hybrid layer and failure of the indirect restoration $^{(38,39)}$.

Immediate dentin sealing seems that it is very important for the retention of endocrowns that depends mainly on adhesion, however, to the authors knowledge no study has evaluated the effect of IDS on the marginal fit of endocrowns that may be also affected by the CAD/ CAM system type (scanner, software and milling ) as mentioned before.

So the aim of this study was to examine the effect of the immediate dentin sealing and CAD/ CAM system on the marginal fit of CAD/CAM endocrowns restoration.

The null hypothesis was neither the immediate dentin sealing nor the CAD/CAM system will affect the marginal fit of endocrowns.

\section{MATERIALS AND METHODS}

To standardize and approximate the clinical situation as much as possible, Forty extracted natural lower first molar teeth of nearly similar dimensions were selected from patients in the out clinics of Oral and Maxillofacial Surgery Department, Faculty of Dentistry, Tanta University suffering from the loosening of their teeth due to sever periodontal disease or uncontrolled diabetes that has no treatment other than extraction .

Each tooth was embedded in a block of self-polymerizing acrylic resin with the long axis perpendicular to the base of the block using a surveyor to ensure the standardization and parallelism to the long axis of the tooth. The acrylic resin ending $2 \mathrm{~mm}$. below the cemento-enamel junction.

Standardized tooth preparation was applied to all specimens. The intact crowns were removed by a horizontal section $4 \mathrm{~mm}$ above the CEJ (at the middle of the buccal and middle of the lingual surface) using a diamond disc attached to a lowspeed straight handpiece with water spray under controlling of a surveyor. A standard access opening was prepared and canals were chemo-mechanically debrided using Protaper Niti rotary files (Dentsply Tulsa Dental, Johnson City, TN) and $\mathrm{NaOCl}$ (5.25\%) irrigation to within $1 \mathrm{~mm}$ of the apex.

Obturation of the canals was performed using gutta-percha and sealer to the orifice level and condensed. After completion of endodontic treatment evenly reduce wall surface of the pulp chamber to expose clean and freshly cut dentin walls and reprepared to be slightly more diverge and standardize the depth of the pulp chamber (fig 1)

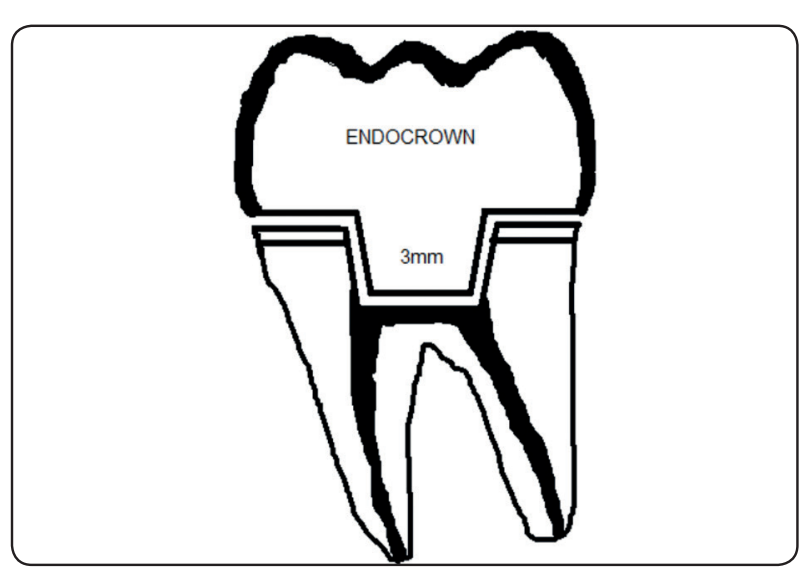

Fig. (1) Diagram of standardized preparation for endocrown restoration

The specimens were assigned to 4 groups $(n=10)$ according to; firstly the type of CAD/CAM system; DOF system and CEREC inLab system. Then according to the timing of dentin sealing; immediate 
dentin sealing (IDS) and delayed dentin sealing (DDS), for each system.

So we had 4 groups gp.1 (DOF, IDS) gp.2 (DOF, DDS) ,gp.3 (CEREC inlab, IDS) gp.4 (CEREC inlab, DDS).

\section{Immediate dentin sealing -IDS.}

Half of the specimens (20 molars in Gp.1,3) were subjected to all the procedures of dentin sealing application immediately after preparation and before scanning as the manufacture instructions (Syntac, IvoclarVivadent, Schaan, Liechtenstein).

$37 \%$ phosphoric acid etching gel was applied to the freshly cut dentin for $15 \mathrm{~s}$, then washed with airwater spray for $20 \mathrm{~s}$., and dried with oil-free air for another $5 \mathrm{~s}$.

The Dentin primer was applied for $15 \mathrm{~s}$. and dried for 10s. After that the dentin adhesive (Syntac) was applied for $10 \mathrm{~s}$. and dried for another $10 \mathrm{~s}$. Adhesive resin (Heliobond,IvoclarVivadent) was applied and air blown to a thin layer for $15 \mathrm{~s}$. The adhesive was light-polymerized for $20 \mathrm{~s}$. using a light-emitting diode curing unit (blue phase curing unit, IvoclarVivadent with a $12 \mathrm{~mm}$. diameter curing-light tip in standard mode with an irradiance output of $1,000 \pm 50 \mathrm{~mW} / \mathrm{cm} 2$, held at a surface-tip distance of $0.5 \mathrm{~mm}$.

Glycerin gel (Liquid Strip, Ivoclar Vivadent) was applied over the teeth, and the dentin bonding agent (DBA) was polymerized for another $20 \mathrm{~s}$, then washed and air-dried to prevent oxygen inhibition of polymerization. Enamel margins of the preparation were finished and cleaned to remove excess adhesive at the marginal area. These procedures were applied to groups $(1,3)$, Then the specimens were imaging sprayed with a CAD powder before scanning.

The other 20 specimens ( Gp.2,4).were scanned after imaging sprayed without any sealing of freshly cut dentin groups.
In case of the DOF system $(\mathrm{Gp} 1,2)$ the prepared teeth were scanned by the DOF white led light optical extra oral scanner using rotational scan mode. The design of endocrowns (fig.2), was done through the supplied software and the calculated STL (standared transformation language) files were transferred to the 5-axis milling machine (CORiTEC 550i; iMES-iCORE milling machine).

In case of CEREC in-lab system the prepared teeth were scanned using In-Eos Blue scanner of sirona which is a blue led light optical extra oral scanner. The scanning was also done with rotational scan technique. The calculated STL (standared transformation language) files(fig.3), are transferred to the 5-axis milling machine (MC XL milling machine, sirona).

All restorations were milled in hybrid ceramic blocks (VITA ENAMIC® for CEREC®/ inLab®,VITAZahnfabrik H. Rauter GmbH \& Co.KG., Germany) under wet milling.

The milling process was fully automated without any interference with two diamond burs acting together simultaneously in the shaping process with copious water cooling sprayed from both directions. After completion of the milling process, the crowns were separated manually from the block holder, and the sprue removed with a diamond cutting instrument.

For all groups, the imaging spray was removed from all teeth by means of water and manual brush.

All endocrowns were then checked over their corresponding teeth for seating (fig.4).The restorations were seated on the prepared teeth and supported under constant weight for estimation of the marginal gap.

The vertical marginal gap (VMG) was measured as the minimum distance from certain landmarked points circumferentially demarked around the endocrown edge ( 24 points) to a line at the tooth margin (Fig.5). 


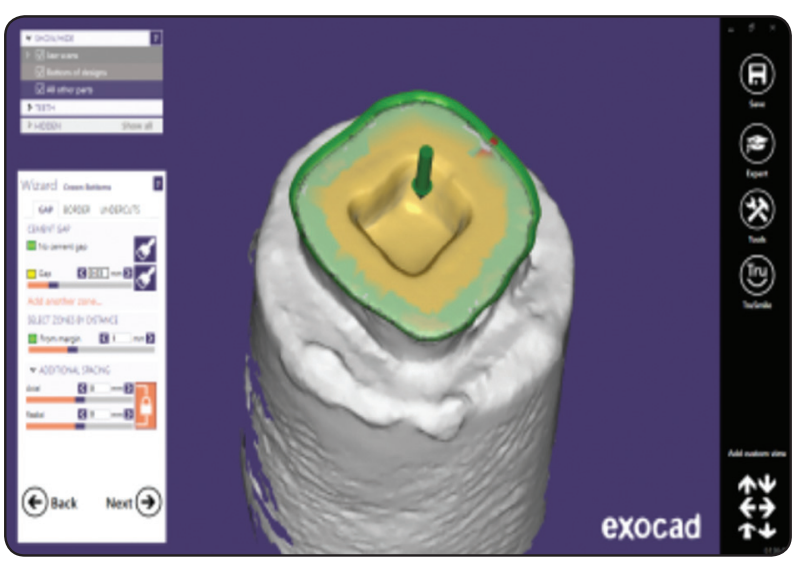

Fig. (2) Scanning with DOF system

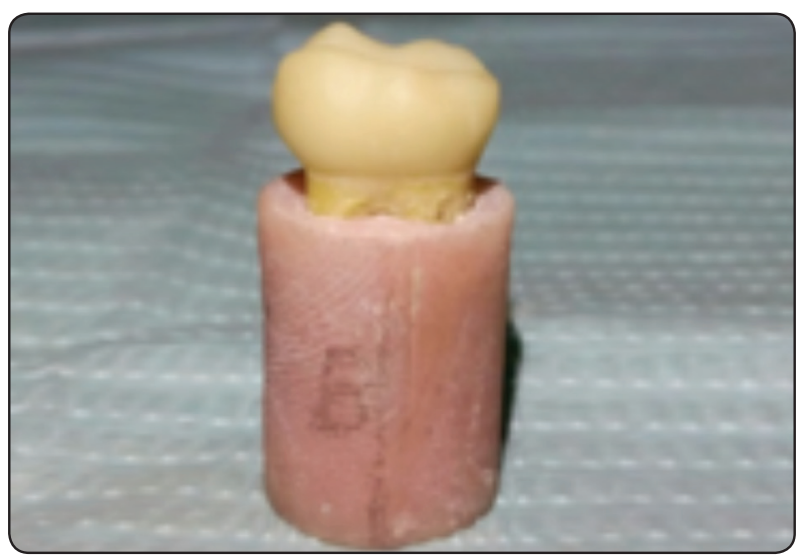

Fig. (4). Endocrown restoration seated on prepared tooth

Measurements were taken without cementation. Each specimen was photographed using measuring Stereomicroscope (Nikon Eclips E600, Tokyo, Japan) connected with an IBM compatible personal computer using a fixed magnification of $45 \mathrm{X}$. A digital image analysis system (Image J 1.43U, National Institute of Health, USA) was used to measure and qualitatively evaluate the gap width. Within the Image J software, all limits, sizes, frames and measured parameters are expressed in pixels.

Therefore, system calibration was done to convert the pixels into absolute real world units. Calibration was made by comparing an object of known size (a ruler in this study) with a scale generated by the Image $\mathrm{J}$ software.

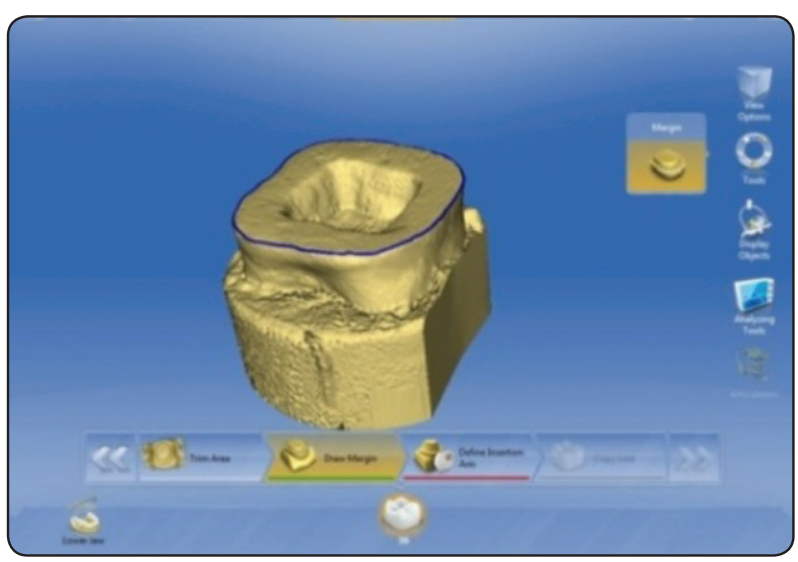

Fig. (3) Scanning with CEREC inlab system

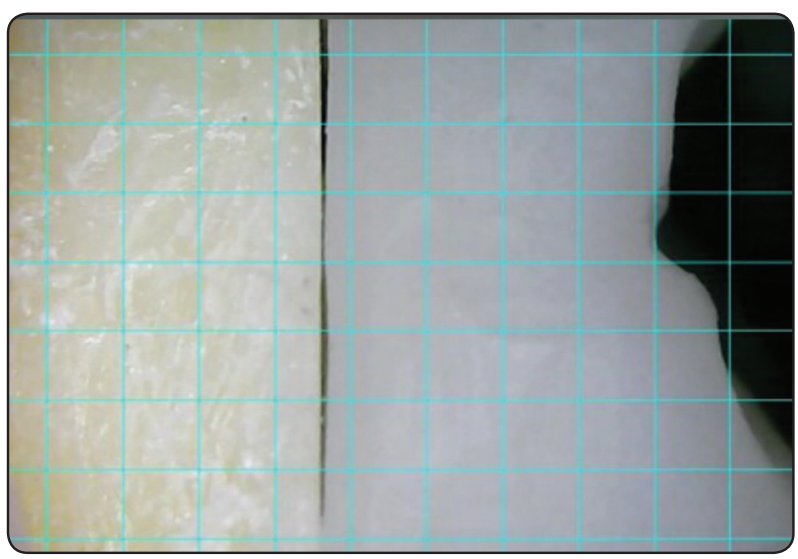

Fig. (5) Measuring The vertical marginal gap (VMG) seated on prepared tooth

Specimens were held in place over their corresponding preparations using a specially designed and fabricated holding device $10 \mathrm{Kg}$ weight. Shots of the margins were taken for each specimen. Then morphometric measurements were done for each shot [ 6 equidistant landmarks along the cervical circumference for each surface of the specimen (Mesial, buccal, distal, and lingual). Measurement at each point was repeated five times.

The means and standard deviations per group were calculated, and the data obtained were collected, tabulated and then subjected to statistical analysis. 


\section{RESULTS}

The means and standard deviations of the marginal fit were $22.4 \pm 10.37 \mu \mathrm{m}$ for the DOF CAD/CAM system after IDS and $14.9575 \pm 4.5$ $\mu \mathrm{m}$ after DDS. However for CEREC inlab system there were $24.4 \pm 10.3 \mu \mathrm{m}$ after IDS and 18.8302 \pm 7.2 after DDS as showing in Table I.

Statistical differences among the 4 groups were made using Kruskal-Wallis test at 0.05 level of significance. Mann Whitney test was performed at 0.01 level of significance to compare marginal fit between the different groups.

A significant difference was found between gps. 1and 2 and between gp 3 and 4. Also between gps. 2 and 4 however there was no significant difference between other groups.

Table (I) The means + the standard deviations of marginal fit in each of the groups. and compression between each two groups.

\begin{tabular}{|c|c|c|c|c|c|c|}
\hline Group & $\mathrm{N}$ & Mean \pm SD & Minimum & Maximum & Kruskal-Wallis test $\left(\mathrm{X}^{2}\right)$ & $P$ value \\
\hline 1 & 10 & $22.4088 \pm 10.375251$ & 8.544 & 51.265 & & \\
\hline 2 & 10 & $14.9575 \pm 4.523385$ & 8.544 & 25.633 & 15.725 & $0.001 *$ \\
\hline 3 & 10 & $24.4088 \pm 10.375251$ & 10.544 & 53.265 & & \\
\hline 4 & 10 & $18.8302 \pm 7.221724$ & 8.544 & 35.229 & & \\
\hline \multicolumn{5}{|c|}{ Comparison between every two groups } & Mann-Whitney test (z) & $P$ value \\
\hline \multicolumn{5}{|c|}{ Group 1, 2} & 2.671 & $0.008^{*}$ \\
\hline \multicolumn{5}{|c|}{ Group 1, 3} & 1.104 & 0.27 \\
\hline \multicolumn{5}{|c|}{ Group 1, 4} & 1.202 & 0.229 \\
\hline \multicolumn{5}{|c|}{ Group 2, 4} & 1.79 & 0.073 \\
\hline \multicolumn{5}{|c|}{ Group 2, 3} & 3.718 & $<0.001^{*}$ \\
\hline \multicolumn{5}{|c|}{ Group 3, 4} & 2.134 & $0.033^{*}$ \\
\hline
\end{tabular}

*Significant.

\section{DISCUSSION}

The aim of this study was to evaluate the effect of immediate dentin sealing on the marginal fit of endocrowns fabricated with 2 different CAD/CAM systems. Based on the results found in this study, the null hypothesis that was neither the immediate dentin sealing nor the CAD/CAM system will affect the marginal fit of endocrowns has to be rejected.

Statistically significant differences were found for the margin fit within the different test groups $(\mathrm{p}<0.05)$. A significant difference was found between Gp. 1 (DOF, IDS) and Gp. 2 (DOF, DDF) .Also between Gp 3 (CEREC, IDS) and Gp.4 (CEREC,DDS), between Gp 2 (DOF, DDF) and 4 (CEREC,DDS).

The results found for all groups showed relatively low standard deviations that mean there is no prominent difference between the specimens.

Many methods have been described for the evaluation of the marginal fit of restorations ${ }^{(40,41)}$. Despite the method applied, there is a consensus about the clinically acceptable marginal gap for 
restorations with $120 \mu \mathrm{m}^{(42)}$. All values found in this study were below this threshold, which is in accordance with the literature published.

In the present study, endo-crowns were chosen as a restoration type to evaluate their fitting accuracy after immediate and delayed sealing. The design of an endo-crown has been intensively described in the literature ${ }^{(43)}$. Endo-crowns are restorations for endo-dontically treated teeth and consist of a circular margin and a central retention cavity inside the pulp chamber. In general, studies to test the fitting accuracy of restorations are conducted with full-contour crown restorations. The design of an endo-crown is far more complex, with many internal angles that may be difficult to mill for CAD/ CAM milling units with their specific instrument geometries $^{(44)}$.

For Both CAD/CAM systems used, the vertical marginal gap of endo-crowns was significantly decreased in case of DDS than IDS. This is maybe because the DBA was applied twice in the case of IDS however it was applied only one time in case of DDS.

This explanation can be supported by the study of Magne and others ${ }^{(45)}$ who evaluated the film thickness of pre-cured adhesive in the immediate dentin sealing technique and the effects of cleaning procedures on film thickness. They concluded that the film thickness of pre-cured adhesives varies greatly by the specific product and by location on the tooth. They also stated that the cleaning procedures that applied,will remove some of the adhesive layer but not all of it.

There was a statistically non-significant difference in the marginal gap between the two CAD/ CAM systems in case of DDS, this may be due to differences in CAM parameters such as instrument diameter, which was confirmed by a recent study ${ }^{(46)}$ that mentioned that these parameters can affect the accuracy of milled restorations. Also, this difference may be due to the dullness or sharpness of burs and number of times they were used before.

The results of this study are not in agreement with Douglas and others who stated that IDS resulted in fewer gap formations ${ }^{(47) .}$

Based on the findings of this study we don't recommend IDS of endocrown preparation if they are made and cemented in the same visit by CAD/ CAM system using intraoral optical impressions since the collagen will not collapse as there is no conventional impression or temporization.

Although we used the same cement space setting $(40 \mu \mathrm{m})$ for both CAD/CAM systems, one limitation of this study is using one set and also only one CAD/CAM material. Some studies have stated that $30 \mu \mathrm{m}$ of virtual cement thickness may significantly increase the VMD compared with those of $50 \mu \mathrm{m}^{(48)}$.

We also neglected the effect of methods used to remove optical spray and the methods of cleaning preparations before final cementation of indirect restorations in case of immediate dentin sealing. All these factors should be taken into consideration in future studies, in addition to the effect of the film thickness of DBA.

\section{REFERENCES}

1. Dietschi D, Duc O, Krejci I, Sadan A. Biomechanical considerations for the restoration of endodontically treated teeth: a systematic review of the literature-Part 1. Composition and micro-and macrostructure alterations. Quintessence International. 2007;38(9):733-43.

2. Edelhoff D, Sorensen JA. Tooth structure removal associated with various preparation designs for anterior teeth. Journal of Prosthetic Dentistry. 2002;87(5):503-9.

3. Krejci I, Duc O, Dietschi D, de Campos E. Marginal adaptation, retention and fracture resistance of adhesive composite restorations on devital teeth with and without posts. Operative Dentistry. 2003;28(2):127-35.

4. Pashley DH, Tay FR, Breschi L, Tjäderhane L, Carvalho RM, Carrilho M, et al. State of the art etch-and-rinse adhesives. Dental materials. 2011;27(1):1-16. 
5. Lin C-L, Chang Y-H, Pa C-A. Estimation of the risk of failure for an endodontically treated maxillary premolar with MODP preparation and CAD/CAM ceramic restorations. Journal of Endodontics. 2009;35(10):1391-5.

6. Bindl A, Mormann WH. Clinical evaluation of adhesively placed Cerec endo-crowns after 2 years-preliminary results. Journal of Adhesive Dentistry. 1999;1:255-66.

7. Bindl A, Richter B, Mörmann WH. Survival of ceramic computer-aided design/manufacturing crowns bonded to preparations with reduced macroretention geometry. International Journal of Prosthodontics. 2005;18(3).

8. Rocca GT, Saratti CM, Poncet A, Feilzer AJ, Krejci I. The influence of FRCs reinforcement on marginal adaptation of CAD/CAM composite resin endocrowns after simulated fatigue loading. Odontology. 2016;104(2):220-32.

9. Chabouis HF, Faugeron VS, Attal J-P. Clinical efficacy of composite versus ceramic inlays and onlays: a systematic review. Dental Materials. 2013;29(12):1209-18.

10. Lima FF, Neto CF, Rubo JH, Santos GC, Santos MJMC. Marginal adaptation of CAD-CAM onlays: Influence of preparation design and impression technique. The Journal of prosthetic dentistry. 2018(in press).

11. Culic B, Gasparik C, Varvara M, Culic C, Dragos C, Silaghi-Dumitrescu L, et al. EVALUATION OF BLEACHING ON A CAD/CAM HYBRID CERAMIC MATERIAL. Studia Universitatis Babes-Bolyai, Chemia. 2017;62(1).

12. Rinke S, Huls A. Marginal accuracy and fracture strength of conventional and copy-milled all-ceramic crowns. International Journal of Prosthodontics. 1995;8(4).

13. Nakamura T, Nonaka M, Maruyama T. In vitro fitting accuracy of copy-milled alumina cores and all-ceramic crowns. International Journal of Prosthodontics. 2000;13(3).

14. Rosentritt M, Plein T, Kolbeck C, Behr M, Handel G. In vitro fracture force and marginal adaptation of ceramic crowns fixed on natural and artificial teeth. International Journal of Prosthodontics. 2000;13(5).

15. Grenade C, Mainjot A, Vanheusden A. Fit of single tooth zirconia copings: comparison between various manufacturing processes. Journal of Prosthetic Dentistry. 2011;105(4):249-55

16. Albert F, El-Mowafy O. Marginal adaptation and microleakage of Procera AllCeram crowns with four cements. The Journal of Prosthetic Dentistry. 2005;93(4):394.
17. Quintas AF, Oliveira F, Bottino MA. Vertical marginal discrepancy of ceramic copings with different ceramic materials, finish lines, and luting agents: an in vitro evaluation. Journal of Prosthetic Dentistry. 2004;92(3):250-7.

18. Rekow E, Silva N, Coelho P, Zhang Y, Guess P, Thompson V. Performance of dental ceramics: challenges for improvements. Journal of Dental Research. 2011;90(8): 937-52.

19. Hamza TA, Ezzat HA, El-Hossary MMK, Katamish HAEM, Shokry TE, Rosenstiel SF. Accuracy of ceramic restorations made with two CAD/CAM systems. Journal of Prosthetic Dentistry. 2013;109(2):83-7.

20. Mjör IA, Toffentti F. Secondary caries: A literature review with case reports. Quintessence International. 2000;31(3).

21. Contrepois M, Soenen A, Bartala M, Laviole O. Marginal adaptation of ceramic crowns: a systematic review. Journal of Prosthetic Dentistry. 2013;110(6):447-54. e10.

22. Fonseca RB, Correr-Sobrinho L, Fernandes-Neto AJ, Quagliatto PS, Soares CJ. The influence of the cavity preparation design on marginal accuracy of laboratory-processed resin composite restorations. Clinical oral investigations. 2008;12(1):53-9.

23. Renne W, McGill ST, Forshee KV, DeFee MR, Mennito AS. Predicting marginal fit of CAD/CAM crowns based on the presence or absence of common preparation errors. Journal of Prosthetic Dentistry. 2012;108(5):310-5.

24. Baig MR, Tan KB-C, Nicholls JI. Evaluation of the marginal fit of a zirconia ceramic computer-aided machined (CAM) crown system. Journal of Prosthetic Dentistry. 2010;104(4):216-27.

25. Mounajjed R, Layton DM, Azar B. The marginal fit of E. max Press and E. max CAD lithium disilicate restorations: A critical review. Dental materials journal. 2016;35(6): 835-44.

26. Jacobs MS, Windeler AS. An investigation of dental luting cement solubility as a function of the marginal gap. The Journal of prosthetic dentistry. 1991;65(3):436-42.

27. Spohr AM, de Oliveira LG, Borges GA, Júnior LHB. The Efficacy of Immediate Dentin Sealing Techniques on Marginal Micro Leakage of Composite Resin Inlays. British Journal of Applied Science \& Technology.2015;9(3): 222230 .

28. Watanabe EK, Yamashita A, Imai M, Yatani H, Suzuki $\mathrm{K}$. Temporary cement remnants as an adhesion inhibiting 
factor in the interface between resin cements and bovine dentin. International Journal of Prosthodontics. $1997 ; 10(5)$.

29. Woody T, Davis R. The effect of eugenol-containing and eugenol-free temporary cements on microleakage in resin bonded restorations. Operative dentistry. 1992;17(5):17580 .

30. Pashley E, Comer R, Simpson M, Horner J, Pashley D, Caughman W. Dentin permeability: sealing the dentin in crown preparations. Operative dentistry. 1992;17(1): $13-20$.

31. Nikaido T, Cho E, Nakajima M, Tashiro H, Toba S, Burrow $\mathrm{M}$, et al. Tensile bond strengths of resin cements to bovine dentin using resin coating. American journal of dentistry. 2003;16:41A-6A.

32. Jayasooriya P, Pereira P, Nikaido T, Burrow M, Tagami J. The effect of a" resin coating" on the interfacial adaptation of composite inlays. Operative Dentistry. 2003; 28(1):28-35.

33. Magne P, Kim TH, Cascione D, Donovan TE. Immediate dentin sealing improves bond strength of indirect restorations. Journal of Prosthetic Dentistry. 2005;94(6):511-9.

34. Islam MR, Takada T, Weerasinghe DS, Uzzaman MA, Foxton RM, Nikaido T, et al. Effect of resin coating on adhesion of composite crown restoration. Dental materials journal. 2006;25(2):272-9.

35. Sultana S, Nikaido T, Matin K, Ogata M, Foxton RM, Tagami J. Effect of resin coating on dentin bonding of resin cement in Class II cavities. Dental materials journal. 2007;26(4):506-13.

36. Duarte S, de Freitas CRB, Saad JRC, Sadan A. The effect of immediate dentin sealing on the marginal adaptation and bond strengths of total-etch and self-etch adhesives. Journal of Prosthetic Dentistry. 2009;102(1):1-9.

37. El-Damanhoury H, Gaintantzopoulou M. The effect of immediate dentin sealing and optical powder removal method on the fracture resistance of CAD/CAM-fabricated endocrowns. International journal of computerized dentistry. 2016;19(2):135-51.
38. Dietschi D, Olsburgh S, Krejci I, Davidson C. In vitro evaluation of marginal and internal adaptation after occlusal stressing of indirect class II composite restorations with different resinous bases. European journal of oral sciences. 2003;111(1):73-80.

39. McCabe J, Rusby S. Dentine bonding--the effect of pre-curing the bonding resin. British dental journal. 1994;176(9):333.

40. Reich S, Uhlen S, Gozdowski S, Lohbauer U. Measurement of cement thickness under lithium disilicate crowns using an impression material technique. Clinical oral investigations. 2011;15(4):521-6.

41. Laurent M, Scheer P, Dejou J, Laborde G. Clinical evaluation of the marginal fit of cast crowns-validation of the silicone replica method. Journal of oral rehabilitation. 2008;35(2):116-22.

42. McLean J. The estimation of cement film thickness by an in vivo technique. Br dent j. 1971;131:107-11.

43. Lander E, Dietschi D. Endocrowns: a clinical report. Quintessence international. 2008;39(2).

44. Zimmermann M, Valcanaia A, Neiva G, Mehl A, Fasbinder D. Three-Dimensional Digital Evaluation of the Fit of Endocrowns Fabricated from Different CAD/CAM Materials. Journal of Prosthodontics. 2018(in press).

45. Stavridakis M, Krejci I, Magne P. Immediate dentin sealing of onlay preparations: thickness of pre-cured dentin bonding agent and effect of surface cleaning. Operative Dentistry-University of Washington-. 2005;30(6):747.

46. Bosch G, Ender A, Mehl A. A 3-dimensional accuracy analysis of chairside CAD/CAM milling processes. Journal of Prosthetic Dentistry. 2014;112(6):1425-31.

47. Magne P, Douglas WH. Porcelain veneers: dentin bonding optimization and biomimetic recovery of the crown. International Journal of Prosthodontics. 1999;12(2).

48. Kale E, Seker E, Yilmaz B, Özcelik TB. Effect of cement space on the marginal fit of CAD-CAM-fabricated monolithic zirconia crowns. Journal of Prosthetic Dentistry. 2016;116(6):890-5. 